\title{
PENGARUH KUAT ARUS DAN WAKTU PELAPISAN NIKEL PADA PLAT BAJA ST 37 DENGAN PROSES ELEKTROPLATING
}

\author{
Ahmad Shobib, Rudi Firyanto, Lisdiana Kusuma Ningrum \\ Program Studi Teknik Kimia Fakultas Teknik Universitas 17 Agustus 1945 Semarang \\ Jl. Pawiyatan Luhur Bendan Dhuwur Semarang \\ E-mail: ahmadshobib@gmail.com
}

\begin{abstract}
Abstrak
Agar logam Nikel tidak mudah rusak yang disebabkan oleh pengaruh lingkungan maupun korosi, maka salah satu cara yang digunakan untuk melakukan perlindungan terhadap korosi adalah dengan memberikan lapisan pelindung dari logam. Salah satu cara pelapisan logam yang dapat dilakukan yaitu dengan metode elektroplating. Pelapisan nikel pada plat St 37 dengan proses elektroplating ini metode yang digunakan adalah metode ANOVA 2 sisi dengan menggunakan variabel waktu dan kuat arus. Hasil yang didapatkan bahwa semakin lama waktu pelapisan yang terjadi maka akan semakin besar dan tebal pelapisan nikel pada plat st 37. Sama halnya dengan variabel kuat arus semakin besar kuat arus, maka berat plat st37 makin bertambah hal ini dikarenakan adanya penambahan pelapisan nikel. Pada penelitian yang telah dilakukan yang paling banyak melapisi plat adalah pada saat waktu 15 menit dan kuat arus sebesar 3 Ampere yaitu 0,82 gram.
\end{abstract}

Kata kunci : Elektroplating, kuat arus, Logam, Nikel, Waktu

\section{PENDAhUluan}

Logam masih banyak digunakan atau dimanfaatkan dalam masyarakat, karena logam mempunyai kelebihan dibandingkan material yang lain yaitu mudah di sambung/ dilas, memiliki harga konduktivitas listrik yang tinggi, konduktivitas panas tinggi dan dapat di haluskan sehingga berkilau permukaanya( Bibit Sugito, dkk. 2015).

Agar logam tidak mudah rusak yang disebabkan oleh pengaruh lingkungan maupun korosi, maka perlu dicari cara untuk melindunginya. Salah satu cara yang digunakan untuk melakukan perlindungan terhadap korosi adalah dengan memberikan lapisan pelindung dari logam. Untuk itu pelapisan logam yang dapat dilakukan yaitu dengan metode elektroplating. Elektroplating atau lapis listrik merupakan salah satu proses pelapisan bahan padat dengan lapisan logam menggunakan bantuan arus listrik melalui suatu elektrolit. (Febriyan Andinata,dkk.2012).

Nikel amat popular dalam plating, terutama pada sistem plating tembaga-nikelkhrom (dekoratif / protektif). Nikel merupakan logam plating yang paling peka responnya atas aditifaditif bak platingnya. Riwayat plating nikel (vernikel) sudah amat kaya. Deposit hasil plating nikel pertama yang baik ialah oleh Bottger (1842). Proses komersial pertama dikembangkan tahun 1870 oleh Adam (Bapak plating nikel). Penggunaan asam borat baru pada akhir abad lalu, kemudian khlorida, untuk mencegah pasivitas anoda baru tahun 1906. Watts, 1916, menemukan formulasi bak plating yang baik. Bak Watts masih digunakan sampai sekarang, tentu saja dengan berbagai perbaikan aditif, konsentrasi dan komposisi anodanya. Nikel khlorida memasok khloridanya. Ini untuk mencegah agar anoda tidak pasif. Deposit nikel amat peka garam khloraida berkation lain. Khlorida juga meningkatkan daya hantar serta daya lontar.( Arsianto dan Ashar. 2018).

Nikel merupakan logam yang banyak digunakan dalam industri pelapisan logam. Nikel mempunyai sifat tahan terhadap korosi, memiliki kekuatan dan kekerasan yang cukup, keliatan yang baik, serta memiliki daya hantar listrik yang baik. Pada proses pelapisan logam, nikel banyak digunakan dengan tujuan sebagai fungsi dekoratif dan juga fungsi aplikatif. Oleh sebab itu nikel dapat dipergunakan dalam aplikasi yang membutuhkan ketahanan terhadap gesekan dan temperature tinggi.

Tujuan pelapisan logam tidak luput dari tiga hal, yaitu untuk meningkatkan sifat mekanis pada subtrat, melindungi subtrat dari korosi dan memperindah tampilan (Anton J.Hartomo dan Tomijiro Kaneko , 1992).

Elektroplating atau lapis listrik merupakan salah satu proses pelapisan bahan padat dengan lapisan logam menggunakan bantuan arus listrik melalui suatu elektrolit. Benda yang dilakukan pelapisan harus merupakan konduktor atau dapat menghantarkan arus listrik. Untuk melindungi logam dengan proses 
electroplating dibutuhkan listrik arus searah (DC), elektrolit yang disesuaikan dengan lapisan yang akan diinginkan, logam pelapis (anoda), dan benda kerja yang akan dilapis (katoda). Didunia industri ada beberapa macam logam pelapis yang sering digunakan dalam proses pelapisan secara elektroplating, yaitu tembaga $(\mathrm{Cu})$, Nikel $(\mathrm{Ni})$, dan krom $(\mathrm{Cr})$. (Febriyan Andinata,dkk.2012)

\section{METODOLOGI}

Metodologi yang digunakan yaitu metode Anova 2 sisi. Dan plat baja ST 37 yang digunakan memiliki dimensi $6 \mathrm{~cm} \times 3 \mathrm{~cm}$ Penelitian dilakukan dengan menerapkan dua variabel. Variabel yang digunakan adalah variabel waktu dan variabel kuat arus. Variabel waktu yang dipakai adalah 5 menit, 10 menit, 15 menit, dan kuat arus yang digunakan 2 Ampere, 2,5 Ampere, 3 Ampere.

Tabel 1.Tabel model analisa metode Anova

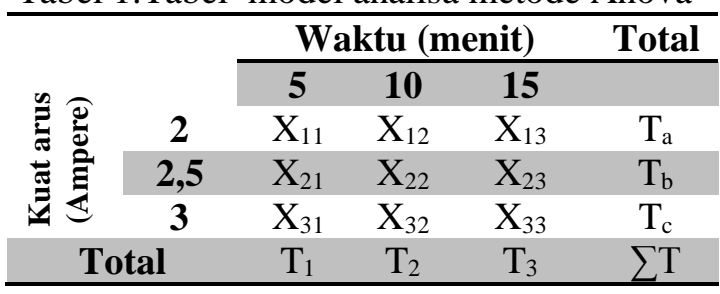

Model $: \mathrm{X}_{\mathrm{ij}}=\mu \mathrm{i}+\alpha_{\mathrm{i}}+\beta_{\mathrm{j}}+\sum \mathrm{ij}$

Dimana $: i=1, \ldots$.

$\mathrm{j}=1, \ldots \mathrm{b}$

$\alpha i=$ Efek dari klasifikasi A ke i

$\beta \mathrm{j}=$ Efek dari klasifikasi $\mathrm{B}$ ke $\mathrm{j}$

Hipotesa :

Untuk variabel A

$\mathrm{Ho}=\alpha \mathrm{i}=0 \rightarrow$ untuk semua harga $\mathrm{i}$

$\mathrm{H} 1=$ Tidak semua $\alpha \mathrm{i}=0$

Untuk variabel B

$\mathrm{Ho}=\beta \mathrm{j}=0 \rightarrow$ untuk semua harga $\mathrm{j}$

H1 $=$ Tidak semua $\beta \mathrm{j}=0$

Dilakukukan hipotesa perhitungan sebagai berikut :

Faktor koreksi

$\mathrm{C}=\frac{\mathrm{T}^{2}}{\mathrm{a} \cdot \mathrm{b}}$

Jumlah kuadrat diantara klasifikasi A

SSA $=\sum_{i=1}^{\mathrm{a}} \frac{\mathrm{Ti}^{2}}{\mathrm{~b}}-\mathrm{C}$
Jumlah kuadrat diantara klasifikasi B

$\mathrm{SSB}=\sum_{\mathrm{j}=1}^{\mathrm{b}} \frac{\mathrm{Ti}^{2}}{\mathrm{a}}-\mathrm{C}$

Jumlah dari kuadrat total

SST $=\sum_{i=1}^{a}=\sum_{j=1}^{b}=\frac{T i^{2}}{a}-C$

Jumlah kuadrat-kuadrat interaksi

$\mathrm{SSE}=\mathrm{SST}-\mathrm{SSA}-\mathrm{SSB}$

Statistik F

$\mathrm{FA}=\frac{\mathrm{MSA}}{\mathrm{MSE}} \quad \mathrm{FB}=\frac{\mathrm{MSB}}{\mathrm{MSE}}$

Pengujian Hipotesa

Ho ditolak bila $\mathrm{F}_{\mathrm{A}}>\mathrm{F} \alpha$ pada signifikasi $\alpha$

Ho diterima apabila $F_{A}<F_{\alpha}$

Pada d k (a-1) dan (a-1)(b-1)

Langkah Percobaan sebelum proses pelapisan dilaksanakan adalah persiapan benda kerja yang digunakan dalam percobaan, serta peralatan yang akan digunakan untuk pengambilan data.

Tahapan persiapan benda kerja meliputi: proses pemolesan dan pembersihan pada benda kerja plat baja ST 37, kemudian membilas benda kerja dengan aquades, tahapan berikutnya adalah proses pencelupan kedalam ke dalam masing-masing larutan alkohol, larutan $\mathrm{Na}_{2} \mathrm{CO}_{3}$, dan larutan $\mathrm{HCL} 10 \%$, sehingga semua kotoran yang masih tertempel pada plat ST37 benar-benar hilang dan bersih pada permukaan plat ST37

Mempersiapkan Larutan elektrolit, dalam hal ini larutan elektrolit yang dipakai dibuat dari garam logam $\mathrm{NiSO}_{4}$. Sebagai katoda dalam hal ini adalah plat ST37 (benda kerja) sebagai elektroda negatif karena memiliki kumpulan atom-atom yang terkait dimana elektronelektronnya dapat bergerak bebas sehingga proses lapis listrik dapat berlangsung dengan baik dan logam dapat menempel kuat pada katoda.

Sedangkan nikel adalah anoda yang berfungsi elektroda positif yang merupakan logam pelapis. Selanjutnya merangkai alat elektroplating dan mengatur sesuai variabel yang diinginkan. Kemudian plat masuk kedalam larutan elektrolit nikel sesuai rangkaian alat berikut ini. 


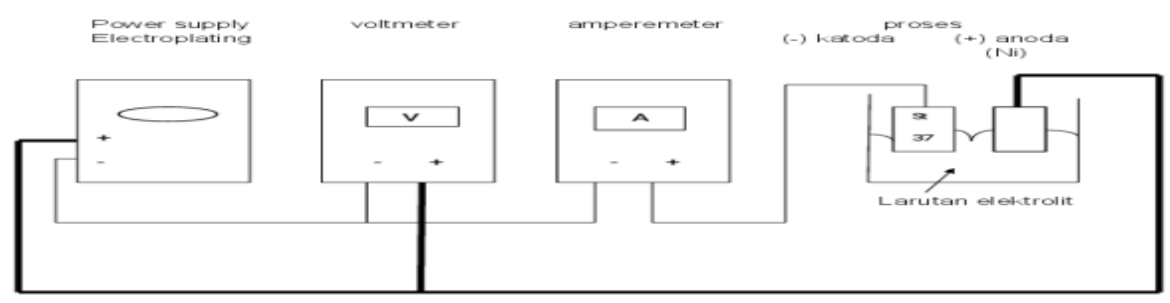

Gambar 1. Rangkaian Alat Elektroplating

\section{HASIL DAN PEMBAHASAN}

Tabel 2. Data Percobaan Pelapisan Nikel pada Plat st 37.

\begin{tabular}{|c|c|c|c|c|c|}
\hline \multirow{2}{*}{$\begin{array}{c}\text { Benda Kerja } \\
\text { Plat st } 37\end{array}$} & \multirow{2}{*}{$\begin{array}{c}\text { Arus Listrik } \\
\text { (Ampere) }\end{array}$} & \multirow{2}{*}{$\begin{array}{c}\text { Waktu } \\
\text { (menit) }\end{array}$} & \multicolumn{2}{|c|}{ Berat (gr) } & \multirow{2}{*}{$\begin{array}{c}\text { Pertambahan } \\
\text { Berat (gr) }\end{array}$} \\
\hline 1 & 2 & 5 & 28.89 & 29.15 & 0.26 \\
\hline 2 & 2 & 10 & 28.96 & 29.38 & 0.42 \\
\hline 3 & 2 & 15 & 30.04 & 30.60 & 0.56 \\
\hline 4 & 2.5 & 5 & 29.17 & 29.51 & 0.34 \\
\hline 5 & 2.5 & 10 & 29.54 & 30.07 & 0.54 \\
\hline 6 & 2.5 & 15 & 29.70 & 30.43 & 0.73 \\
\hline 7 & 3 & 5 & 28.80 & 29.23 & 0.43 \\
\hline 8 & 3 & 10 & 29.58 & 30.22 & 0.64 \\
\hline 9 & 3 & 15 & 29.79 & 30.61 & 0.82 \\
\hline
\end{tabular}

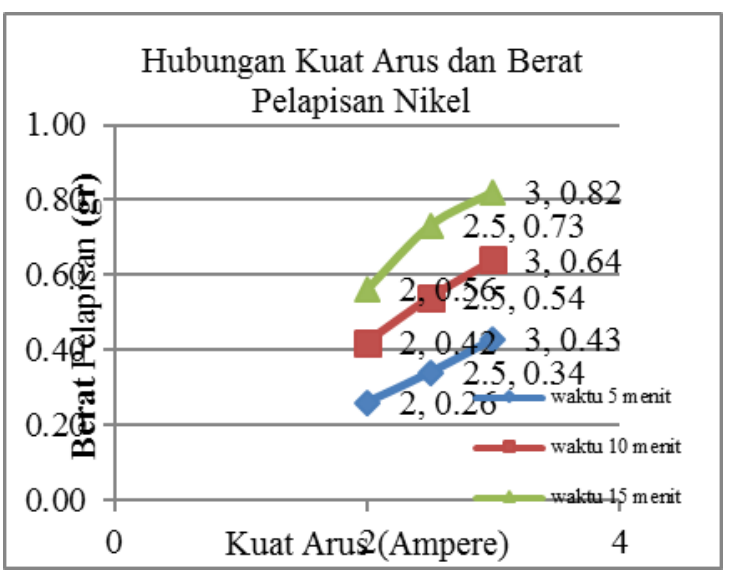

Gambar 2. Hubungan kuat arus dan berat pelapisan nikel

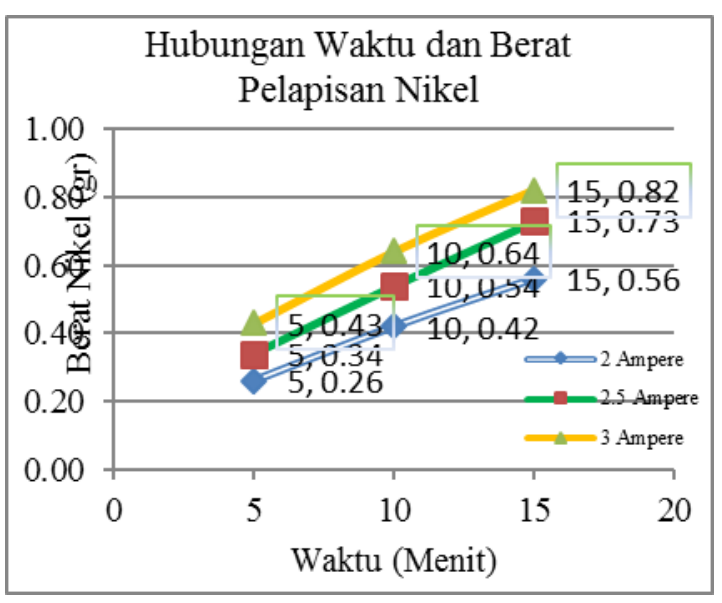

Gambar 3. Hubungan waktu dan berat pelapisan nikel
Pada Tabel 2 dapat dilihat bahwa makin tinggi kuat arus dan lama waktu mengalami penambahan berat pelapisan pada plat st 37 . Hal ini bisa terlihat pada kuat arus 3 Ampere waktu 15 menit berat pelapisan yang di hasilkan merupakan berat pelapisan yang terbesar yaitu 0.82 gram, sehingga semakin besar kuat arus dan lama waktu yang digunakan maka semakin besar juga hasil berat pelapisan yang di dapatkan.

Dalam gambar 2 dapat kita ketahui bahwa hubungan antara besar arus yang digunakan dan lamanya waktu dalam proses elektroplating nikel sangat berpengaruh terhadap berat logam nikel yang terlapis. Hal ini disebabkan karena dengan meningkatnya kuat arus listrik yang mengalir dan lama waktu proses elektroplating nikel maka jumlah ion ion semakin banyak, sehingga ion- ion banyak yang terlepas dari larutan dan mengendap pada katoda/ benda kerja.

Sedangkan hubungan antara lama waktu dalam proses elektroplating yang disajikan dalam gambar 3 mempengaruhi berat logam nikel yang terlapis. Dengan besar arus yang digunakan sama dan luas permukaan benda kerja yang sama, dengan beberapa kali percobaan, dimana setiap kali percobaan lama waktu pelapisan yang digunakan maka semakin naik berat hasil pelapisan nikel yang dihasilkan. Hal ini dikarenakan pada anoda dan katoda 
terjadi perbedaan potensial setelah dialiri listrik, maka logam nikel akan teroksidasi menjadi ion logam bermuatan positif $\left(\mathrm{Ni}^{2+}\right)$, ion logam nikel $\left(\mathrm{Ni}^{2+}\right)$ dari anoda larut dalam larutan untuk menggantikan ion logam nikel $\left(\mathrm{Ni}^{2+}\right)$ dari garam logam $\mathrm{NiSO}_{4}$ yang telah terelektrolisis menjadi $\mathrm{Ni}^{2+}$ dan $\mathrm{SO}_{4}{ }^{2-}$ dan tertarik ke katoda untuk membentuk lapisan nikel. Dengan adanya hal tersebut akan terbentuk endapan pada katoda yang berupa berat lapisan. Sehingga semakin lama waktunya, mengakibatkan semakin banyak Endapan yang melapisi plat st 37.

Berdasarkan penelitian yang telah dilakukan diperoleh data-data yang selanjutnya diolah dengan menggunakan metode anova yang hasilnya disajikan dalam Tabel 3 dan Tabel 4.

Tabel 3. Tabel data analisa metode Anova dari hasil percobaan.

\begin{tabular}{|c|c|c|c|c|c|}
\hline & \multicolumn{3}{|c|}{ Waktu (menit) } & \multirow[t]{2}{*}{ Total } \\
\hline & & 5 & 10 & 15 & \\
\hline \multirow{3}{*}{ 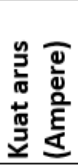 } & 2 & $0,26 \mathrm{gr}$ & $0,42 \mathrm{gr}$ & $0,56 \mathrm{gr}$ & $1,23 \mathrm{gr}$ \\
\hline & 2,5 & $0,34 \mathrm{gr}$ & $0,53 \mathrm{gr}$ & $0,73 \mathrm{gr}$ & $1,60 \mathrm{gr}$ \\
\hline & 3 & $0,43 \mathrm{gr}$ & $0,64 \mathrm{gr}$ & $0,82 \mathrm{gr}$ & $1,89 \mathrm{gr}$ \\
\hline \multicolumn{2}{|c|}{ Total } & $1,03 \mathrm{gr}$ & $1,59 \mathrm{gr}$ & $2,11 \mathrm{gr}$ & $4,73 \mathrm{gr}$ \\
\hline
\end{tabular}

Faktor koreksi

$\mathrm{C}=\frac{4,73^{2}}{3 \times 3}=2,486$

Jumlah kuadrat diantara klasifikasi A

SSA $=\frac{1,23^{2}+1,60^{2}+1,89^{2}}{3}-2,486=0,0623$
SSB $=\frac{1,03^{2}+1,59^{2}+2,11^{2}}{3}-2,486=0,1944$

Jumlah dari kuadrat total

SST $=\left(0,26^{2}+0,42^{2}+\ldots \ldots \ldots \ldots+0,64^{2}+\right.$ $\left.0,82^{2}\right)-2,486=0,02679$

Jumlah kuadrat-kuadrat interaksi

$\mathrm{SSE}=\mathrm{SST}-\mathrm{SSA}-\mathrm{SSB}=0,02679-0,0623-$ $0,1944=0,0112$

\section{Statistik F}

$$
\begin{aligned}
& \mathrm{FA}=\frac{0,0311}{0,0028}=11,107 \\
& \mathrm{FB}=\frac{0,0972}{0,0028}=34,714
\end{aligned}
$$

Pada $\alpha=0,05$ dengan $\mathrm{d} \mathrm{k}$ (kuat arus) $=2 ; 4 \rightarrow$ $\mathrm{d} \mathrm{k}($ waktu $)=2 ; 4$

$\mathrm{F}_{0,05}=6,9443$ (kuat arus) $; \mathrm{F}_{0,05}=6,9443$ (waktu)

$\mathrm{F}>\mathrm{F}_{0,05} \quad$ Ho untuk kuat arus ditolak $\rightarrow$ adanya pengaruh kuat arus

$\mathrm{F}>\mathrm{F}_{0,05} \quad$ Ho untuk waktu ditolak $\rightarrow$ adanya pengaruh waktu

Pada penelitian yang telah dilakukan pada proses elektroplating didapatkan hasil yang berpengaruh melapisi plat st 37 adalah waktu dan kuat arus. Hal ini ditunjukkan dengan semakin lama waktu dan semakin tinggi kuat arus, pelapisan nikel semakin besar. Dari hasil uji analisa metode Anova diketahui bahwa adanya interaksi hipotesa ( Ho ) untuk Variasi waktu (A) dan kuat arus (B) ditolak pada $\alpha=0,05$. Dapat dilihat yang banyak melapisi plat adalah pada waktu 15 menit dan kuat arus sebesar 3 Ampere sebesar 0,82 gram.

Jumlah kuadrat diantara klasifikasi B

Tabel 4. Hasil Perhitungan Metode Anova

\begin{tabular}{|l|l|l|l|}
\hline Sumber Variasi & $\begin{array}{l}\text { Derajat } \\
\text { Kebebasan }\end{array}$ & $\begin{array}{l}\text { Jumlah } \\
\text { Kuadrat }\end{array}$ & Nilai Rata-Rata Kuadrat (Mean Square) \\
\hline $\begin{array}{l}\text { Diantara Klasifikasi } \\
\text { Kuat Arus }\end{array}$ & $\begin{array}{l}(3-1) \\
2\end{array}$ & 0,0623 & MSA $=\frac{0,0623}{3-1}=0,0311$ \\
\hline $\begin{array}{l}\text { Diantara Klasifikasi } \\
\text { Waktu }\end{array}$ & $\begin{array}{l}(3-1) \\
2\end{array}$ & 0,1944 & MSB $=\frac{0,1944}{3-1}=0,0972$ \\
\hline Penyimpangan & $\begin{array}{l}(3-1)(3-1) \\
4\end{array}$ & 0,0112 & MSE $=\frac{0,0112}{(3-1)(3-1)}=0,0028$ \\
\hline Total & $\begin{array}{l}(3 \times 3)-1 \\
24\end{array}$ & 0,02679 & \\
\hline
\end{tabular}




\section{KESIMPULAN}

Berdasarkan hasil penelitian yang dilakukan didapatkan kesimpulan sebagai berikut : Hasil percobaan ini menunjukkan bahwa dengan Metode Elektroplating pelapisan nikel pada plat baja ST 37 bisa jadi salah satu metode efektif untuk melapisi suatu besi agar tidak korosi, Pada penelitian yang telah dilakukan pada proses elektroplanting didapatkan hasil yang berpengaruh melapisi plat st 37 adalah waktu dan kuat arus. Hal ini bisa terlihat pada kuat arus 3 Ampere pada waktu 15 menit berat pelapisan yang di hasilkan merupakan berat pelapisan yang terbesar yaitu 0.82 gram. Hal ini juga di analisa dengan metode analisa anova adanya interaksi hipotesa $\left(\mathrm{H}_{0}\right)$ untuk Variasi waktu (A) dan kuat arus (B) ditolak pada $\alpha=0,05$.

\section{UCAPAN TERIMA KASIH}

Dengan segala kerendahan hati penyusun mengucapkan terimakasih kepada Jajaran Dekanat Fakultas Teknik Universitas 17 Agustus 1945 Semarang yang memberikan support dalam hal pendanaan, Program Studi Teknik Kimia Universitas 17 Agustus 1945 Semarang yang telah memfasilitasi Laboratorium sehingga kami dapat melakukan dan menyelesaikan penelitian. Tak lupa teman teman yang selalu memberikan motivasi serta semua pihak yang tidak bisa penyusun sebutkan satu persatu.

\section{DAFTAR PUSTAKA}

Anandita, Febryan; destyorini, Fredina; Sugiarti, Eni; , Munasir; Zaini T, Kemas A. 2012. Pengaruh pH Larutan Elektrolit Terhadap Tebal Lapisan Elektroplating Nikel pada Baja ST 37. Surabaya.Jurnal Penelitian dan Aplikasinya (JPFA) Jurusan Fisika FMIPA Universitas Negeri Surabaya.

Arsianto, Ashar, 2018. Teknik Pelapisan Logam dengan Cara Listrik (Elektroplating), Balai Besar Logam dan Mesin: Bandung. Hartomo, Anton J; Kaneko, Tamijiro. 1992. Mengenal Pelapisan Logam( Elektroplating). Yogyakarta: Andi Offset. Sugito, Bibit; IP, Pramuko; Supriyadi, Agung. 2015. Pengaruh Temperatur Dyeing Pada Proses Anodizing Terhadap Ketebalan dan Laju Korosi Untuk Bahan Cor Kuningan. Universitas Muhammadiyah Surakarta. 